\title{
Non-Necrotizing Granuloma
}

National Cancer Institute

\section{Source}

National Cancer Institute. Non-Necrotizing Granuloma. NCI Thesaurus. Code C113731.

A granuloma that is not associated with necrotic changes. The majority of cases are of non-infectious origin. Causes include sarcoidosis, hypersensitivity pneumonitis, drug reactions, and Crohn disease. 